\title{
Maconha e Representações Sociais em Matérias de Jornal
}

\author{
Yuri Sá Oliveira Sousa ${ }^{1,}$, , Maria de Fátima de Souza $\operatorname{Santos}^{2}$, \& Renata Lira dos Santos Aléssio \\ ${ }^{1}$ Universidade Federal da Bahia, Salvadro, BA, Brasil \\ ${ }^{2}$ Universidade Federal de Pernambuco, Recife, PE, Brasil
}

\begin{abstract}
RESUMO - A maconha é um objeto social polêmico e polissêmico no contexto brasileiro, sendo constantemente debatida em produções midiáticas. A pesquisa objetivou analisar a construção de representações sociais da maconha a partir de 489 matérias do jornal Folha de S. Paulo (2010-2012). Os dados foram tratados com o software ALCESTE e analisados a partir de seis campos léxicos organizados em dois eixos temáticos: repressão policial ao tráfico de drogas e tensões normativas do uso medicinal e recreativo. Os discursos suscitam dimensões individuais e coletivas relacionadas ao status legal do objeto, seus usos e formas de controle social - coercivas e normativas -, que inscrevem simbolicamente a maconha em disputas sociais de identidades, práticas e instituições.
\end{abstract}

PALAVRAS-CHAVE: maconha, mídia, comunicação, representações sociais

\section{Marijuana and Social Representations in Newspaper's Articles}

\begin{abstract}
Marijuana is a controversial and polysemic social object in Brazil, which is constantly discussed in the media. This study aimed to analyze the construction of social representations of marijuana from 489 articles of the newspaper Folha de S. Paulo (2010-2012). The data were treated with the software ALCESTE and analyzed based on six lexical fields organized in two thematic axes: police repression to drug trafficking and normative tensions of the medicinal and recreational use. The discourses raise individual and collective dimensions related to the legal status of the object, its uses and forms of social control - coercive and normative - that symbolically inscribe marijuana in social disputes of identities, practices and institutions.
\end{abstract}

KEYWORDS: marijuana, media, communications, social representations

No contexto das drogas psicoativas, a maconha tem sido amplamente discutida, promovendo controversos debates em campos como os da saúde, direito, economia e segurança pública. $\mathrm{O}$ estudo realizado e aqui apresentado teve o objetivo de analisar a construção de representações sociais da maconha em matérias de jornal. Trata-se de buscar compreender os temas e discursos que constroem esse objeto na cena pública brasileira, evidenciando a sua relação com diferentes fenômenos e processos psicossociais.

Em termos globais de consumo, a maconha é a droga mais utilizada entre usuários de substâncias ilícitas, contando com uma estimativa de que 183 milhões de pessoas tenham consumido a droga em 2014 (United Nations Office on Drugs and Crime [UNODC], 2016). No contexto brasileiro, estima-se que $5,7 \%$ dos estudantes do ensino fundamental e médio (Carlini et al., 2010) e $8,8 \%$ da população geral tenham feito uso da maconha pelo menos uma vez na vida (Carlini et al., 2006).

$\mathrm{O}$ uso crônico de maconha tem sido associado ao potencial desenvolvimento de dependência, prejuízos à memória e desenvolvimento de transtornos psicóticos em indivíduos vulneráveis (NIDA, 2016). Além disso, com frequência as comunicações científicas associam o uso de maconha a transtornos de ansiedade e humor, no entanto, conforme demonstrou um amplo estudo longitudinal (Blanco et al., 2016), não há evidências de relação significativa nesse sentido quando outras variáveis preditoras são consideradas.

Os aspectos relacionados ao consumo individual e coletivo da maconha são úteis para evidenciar a sua relevância no âmbito da saúde. No entanto, como um objeto inscrito em práticas sociais, imbuído de significados culturais e regulado por normas jurídicas, a maconha é simbolicamente construída e ancorada em processos históricos que lhe dão

*E-mail: yurisousas@gmail.com 
forma contemporânea. De acordo com Carlini (2006), costuma-se atribuir a entrada da maconha no Brasil, a partir de 1549, aos negros escravizados, visto ser essa droga, por muito tempo, parte importante da cultura afro do Norte e do Nordeste (MacRae \& Simões, 2003). Na segunda metade do século XIX, começou a se difundir o conhecimento sobre os seus efeitos psicoativos e, além disso, o uso medicinal da planta passou a ser mais popular. Até a década de 1930 a cannabis ainda constava nos compêndios médicos como um medicamento, mas foi nessa mesma década que o movimento de repressão ao seu uso ganhou aderência no Brasil e, em 1936, a sua proibição foi promulgada (MacRae \& Simões, 2003). Precedida por campanhas explicitamente racistas, que apelavam à origem africana da droga, a proibição ganhou contornos higienistas e passou a conceber o consumo da maconha como um flagelo social, uma ameaça à ordem e à raça brasileira (França, 2015).

Durante os anos 50, a cannabis passou a ser largamente discutida em meios de comunicação de massa e, nesse período, a droga passou a ser associada à delinquência e à doença mental (MacRae \& Simões, 2003). A partir dos anos 60, como descreve Velho (1994), o uso de cannabis ganha significados novos, sendo associado a um ideal ou estilo de vida alternativo, a movimentos de liberdade amorosa, sexual e material. Apesar de não se poder tratar como um movimento homogêneo, esse estilo de vida tem estreita relação com uma crescente popularização da maconha em determinados grupos e movimentos, como é o caso dos hippies e da contracultura nos anos 70 (França, 2015).

Em que pese uma aparente aceitação, durante o regime militar houve mais uma onda de alarme social em torno da maconha, cujo centro da discussão era a juventude de classe média. Esses jovens configuravam uma nova "classe perigosa" e representavam uma ameaça cultural ao país por levantar questões sobre transformações sociais. A partir dos anos 80 , o uso recreativo e não problemático da droga ganhou mais aceitação em grandes setores da classe média, mas essa aceitação passa a coexistir com os elementos anteriores, de cunho predominantemente negativo (MacRae $\&$ Simões, 2003).

Ao longo da trama histórica, é possível perceber que a maconha é construída ativamente na cena pública e comporta tensões discursivas que repercutem no contexto atual. Por exemplo, a associação histórica da maconha à doença mental e criminalidade contribuiu para o processo de desqualificação dos seus usuários, de modo que o drogado, viciado ou maconheiro constitui atualmente um rótulo moral que coloca os sujeitos na posição de desviantes (Bucher \& Oliveira, 1994; Oliveira, Gianordoli-Nascimento, Santos, \& Freitas, 2015). Além disso, o objeto se apresenta como alvo de tensões normativas, a partir das quais se delineiam formas de uso consideradas legítimas ou proscritas, aspecto esse que produz, entre outras coisas, o debate sobre o seu status legal e utilidade terapêutica. A esse respeito, destacam-se as recentes iniciativas de regulamentação da maconha no Uruguai, no Canadá e em algumas regiões dos Estados Unidos, bem como da autorização, no Brasil, da prescrição e importação de medicamentos com delta9-tetra-hidrocanabinol (THC) e/ou canabidiol (CBD) pela Agência Nacional de Vigilância Sanitária (ANVISA) em 2016 (Brasil, 2016).

Abordar a maconha como objeto de pesquisa no âmbito da Teoria das Representações Sociais (TRS), por sua vez, significa se debruçar sobre os processos de construção social da realidade através de interações cotidianas. Como formas de pensamento social, as representações sociais possuem a função de interpretar e tornar familiar a realidade, orientando condutas e viabilizando a comunicação (Jodelet, 1984). De acordo com Moscovici (2012), o conceito de representação social se refere a "uma modalidade de conhecimento particular, tendo a função de elaboração dos comportamentos e da comunicação entre os indivíduos" (p. 27). São construções dinâmicas e interativas da realidade social (Banchs, 2011), que produzem um mundo de objetos "domesticados" linguisticamente, que podemos manipular e lidar simbolicamente (Wagner, 1998). É a partir dessa dinâmica de construção e familiarização, de apropriação e reelaboração da realidade que a maconha e outros objetos sociais são construídos na cena pública.

De acordo com Moscovici (2009), as representações são produzidas a partir de dois processos sociocognitivos interdependentes. O primeiro, a objetivação, é responsável por concretizar e cristalizar aspectos abstratos da realidade a partir da seleção de determinadas características e conteúdos salientes em determinado contexto. O segundo, a ancoragem, funciona com base na inserção do objeto num sistema de pensamentos preexistentes, classificando-o através de categorias já conhecidas.

As trocas comunicativas perpassam toda a construção conceitual da Teoria das Representações Sociais, aspecto salientado por Jodelet (2001) quando diz que "a comunicação social, sob seus aspectos interindividuais, institucionais e midiáticos, aparece como condição de possibilidade e de determinação das representações e do pensamento sociais" (p. 30). Nesse processo de construção, os meios de comunicação de massa desempenham uma importante função na organização e difusão dos discursos produzidos na cultura, constituindo um campo de crescente interesse para a análise de representações sociais (Simoneau \& Oliveira, 2014).

Apesar disso, poucos estudos têm abordado o papel das mídias na difusão e organização de representações sociais no contexto temático das drogas e, dentre esses, destacam-se análises a respeito do crack como objeto social. Em estudo realizado sobre o crack e a adolescência na imprensa pernambucana, Espíndula, Alves, Almeida e Cruz (2015) chamam a atenção para a organização dos discursos midiáticos em dois grandes eixos: de um lado, o tratamento do usuário ou sua internação, com pouca probabilidade de sucesso e, de outro lado, a morte do sujeito pelo tráfico de drogas. A ameaça das drogas, a internação do usuário e o tráfico também aparecem como discurso organizador das 
matérias analisadas em um jornal brasiliense por Rodrigues, Conceição e Iunes (2015) sobre o crack. Santos, Acioli Neto e Sousa (2012), ao analisar as representações sociais de crack na imprensa pernambucana, chamam a atenção para os discursos que objetivam o crack no tráfico e na violência, praticada por traficantes ou, ainda, por usuários, os quais são descritos como pessoas fora de si, incapazes de se livrar da dependência.
A despeito da importância desses trabalhos, persiste a necessidade de se analisar a construção da maconha em meios de comunicações de massa. Nessa direção, abordar a difusão de representações sociais a partir das publicações de um jornal de grande circulação no país constitui um meio pertinente de analisar as formas de construção do objeto, seus temas e tomadas de posição (explícitas ou não) na arena pública.

\section{MÉTODO}

\section{Fontes}

Foram analisadas 489 matérias de um jornal de grande circulação nacional - a Folha de S. Paulo -, que assume em seu projeto editorial o propósito de discutir questões de relevância social para o contexto brasileiro. A Folha é um jornal que pretende ser informativo, apartidário, crítico e plural, abordando aspectos diversos da sociedade e não privilegiando posicionamentos unívocos (Pinto, 2012). Independente de atingir seus objetivos, as intenções comunicativas do jornal permitem compreendê-lo como um meio de difusão de representações sociais (Moscovici, 2012), cuja função é criar um conhecimento social comum de modo adaptado às expectativas de um público não estruturado (Doise, 2011).

\section{Procedimentos de Coleta}

Foram coletadas em formato de texto todas as matérias que tinham a maconha como mote central, publicadas durante um período de dois anos (01/07/2010 a 31/07/2012). A coleta do material foi realizada em meio digital, através de buscas detalhadas em bancos de dados do jornal e restringiuse às publicações que citavam no título um dos seguintes descritores: maconha, cânhamo, cannabis e canábis. Esse procedimento foi realizado com o intuito de homogeneizar os dados, visto que muitas matérias faziam apenas menção ao objeto, mas tratavam de discutir, de fato, outros temas. O título, por sua vez, constitui um indicador do tema central da publicação, evitando uma possível dispersão dos dados.

O intervalo de tempo adotado foi definido por critérios de conveniência, com o objetivo de compor um corpus suficientemente relevante e diverso em seu conteúdo, mas que também é pertinente por duas outras razões. A partir de 2010, o conteúdo digital da Folha passa a ser produzido pela mesma equipe do jornal impresso (Pinto, 2012), equiparando os conteúdos do seu webjornalismo (Pernisa \& Alves, 2010) àqueles produzidos tradicionalmente para meio impresso. Em segundo lugar, o período antecedeu importantes transformações no âmbito político com relação à maconha, tais como: a sua regulamentação no Uruguai e em algumas regiões dos Estados Unidos; a aprovação no Brasil da importação de medicamentos derivados da cannabis; e o desenvolvimento de projetos legislativos que propõem a sua regulamentação no país. Nesse sentido, a análise pode auxiliar na compreensão de alguns dos processos comunicacionais que acompanharam tais transformações.

\section{Procedimentos de Análise}

Os dados coletados foram submetidos a um procedimento estatístico de análise textual, com o auxílio do software ALCESTE - Analyse des Lexèmes Cooccurrents dans les Enoncés Simplifiés d'un Texte (Reinert, 2000) - Versão 2010. Esse software funciona com base na coocorrência de palavras em segmentos de texto, havendo o pressuposto de que o uso de vocabulários distintos, ou "mundos lexicais", permite identificar campos semânticos específicos (Nascimento \& Menandro, 2006). Inicialmente, o ALCESTE dividiu cada matéria em Unidades de Contexto Elementar (UCE), ou segmentos de texto, de acordo com critérios automáticos baseados no número de palavras e pontuação. Em seguida, os dados foram submetidos a uma Classificação Hierárquica Descendente (CHD), um processo de análise baseado no contraste entre agrupamentos de segmentos de texto, que permite identificar classes de campos léxicos, bem como suas formas linguísticas características. O resultado desse procedimento é apresentado em um dendrograma que contém as formas reduzidas das principais ocorrências de cada classe e seus respectivos índices de qui-quadrado $\left(\chi^{2}\right)$, os quais representam o grau de associação entre a palavra e o conjunto de segmentos de texto. Cada classe lexical resultante do processo pode ser considerada um contexto semântico que agrupa diferentes enunciados em função do vocabulário compartilhado (Justo \& Camargo, 2014).

Uma vez identificadas as classes lexicais, foram realizados procedimentos de análise de conteúdo com base nos segmentos de texto característicos recuperados em seus contextos de enunciação. Esse procedimento fundamentase na compreensão de que o sentido dos enunciados é produzido pelo próprio uso da linguagem, de modo que os resultados do tratamento do ALCESTE devem ser refletidos de modo inseparável à dimensão pragmática da produção discursiva sobre o objeto (Kalampalikis \& Moscovici, 2005). Por fim, as diferentes classes identificadas foram analisadas, categorizadas e nomeadas em função das relações semânticas produzidas nas e entre as classes. 


\section{RESULTADOS E DISCUSSÃO}

Após o tratamento das 489 matérias, o ALCESTE dividiu o material em $2771 \mathrm{UCE}$. Ao final do procedimento de Classificação Hierárquica Descendente, o software distribuiu 2354 UCE (84,95\%) em seis classes lexicais. As formas léxicas características de cada uma delas podem ser observadas no dendrograma (Figura 1).

Conforme observado na Figura 1, as seis classes foram distribuídas em dois grandes eixos, o primeiro comportando as classes 1 e 4 e o segundo engloba as classes 2, 6, 5 e 3. O primeiro eixo, chamado de "maconha: um caso de polícia", diz respeito à construção da maconha como um objeto relacionado ao tráfico de drogas e manipulado pela polícia como uma mercadoria ilícita. Nele, aplica-se a norma proibicionista, relacionando a maconha a mecanismos de controle social coercitivos. O segundo, classificado como "uso de maconha e tensões normativas", se refere às dimensões individuais e coletivas do uso de maconha em suas relações com os campos da saúde, da política e do direito. De modo específico, são implicados processos de negociação, ilustrados pelo debate sobre as formas e finalidades de uso da maconha e sua regulação através de leis ou valores morais, que produzem possibilidades e interditos nas relações dos sujeitos com a droga. A oposição entre os eixos identificados pode ser interpretada pela relação dos seus respectivos conteúdos com formas específicas de relações de poder. De um lado, evidencia-se o poder coercitivo, caracterizado pela imposição de normas através da força e, de outro, destaca-se o poder normativo, entendido como um empreendimento de caráter simbólico, que funciona através da negociação de normas e valores sociais (Moscovici, 2011).

A apresentação dos resultados considera, sempre que necessário, outros dados fornecidos pelo tratamento do ALCESTE, tais como ausências significativas, expressões e UCE características da classe. Esses elementos são abordados com o objetivo de discutir as particularidades de cada forma de discurso, além de permitir ilustrar a análise realizada a partir de enunciados característicos.

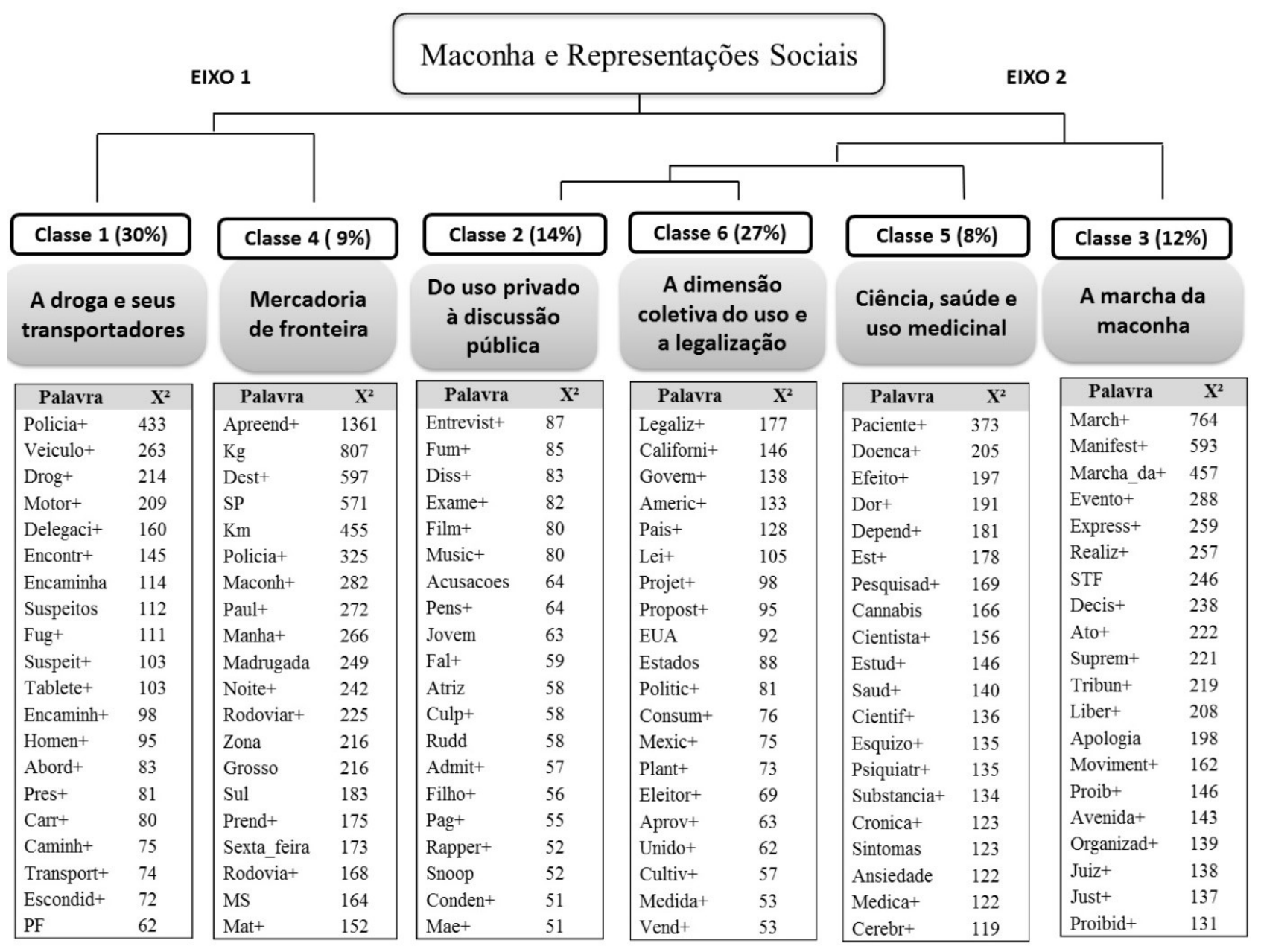

Figura 1. Dendrogram a elaborado a partir dos resultados do ALCESTE. 


\section{Eixo I:“Maconha: um Caso de Polícia”}

Classe 1: A droga e os transportadores. O conteúdo encontrado na classe 1 apresenta uma relação direta entre a maconha e a atuação da polícia na repressão ao tráfico de drogas. A maconha é aqui situada como uma mercadoria, uma droga, apreendida durante o seu transporte. Como é possível observar no dendrograma, a presença de palavras como polícia, delegacia, suspeitos, abordagem, $\mathrm{PF}$, entre outras, denota um vocabulário específico, exemplificado a seguir:

Após vistoriar o caminhão, os policiais encontraram a droga escondida em um compartimento falso na carroceria. $O$ motorista foi preso e levado à delegacia de Boituva.

Nota-se, ainda, a presença de palavras como veículo, motorista, carro e caminhão, que caracterizam as ações policiais descritas nessa classe como especificamente voltadas à logística do tráfico de maconha. De acordo com Magalhães (2000), diferente da cocaína, a maconha do Brasil tem a sua produção principalmente dentro do país. Quando produzida em larga escala, o transporte é feito prioritariamente por terra, através de carros e caminhões que levam a droga das regiões de plantio a diferentes cidades.

O que se observa nessa classe, portanto, são narrativas de interceptação da maconha pela polícia em uma das etapas envolvidas na economia da droga, o processo de transporte. A classe reúne discursos descritivos e, por vezes, "assépticos" no tratamento do tema. A maconha, por sua vez, é discutida genericamente pela nomenclatura de "droga". O próprio termo "maconha" é uma ausência significativa $\left(\chi^{2}=\right.$ -88) em relação à classe. O objeto é produzido como apenas uma dentre outras drogas sem que as relações de consumo ou demanda sejam implicadas. Uma ilustração disso é o fato de o termo "uso" ter uma ausência significativa em relação à classe $\left(\chi^{2}=-63\right)$. A maconha é, então, tratada como uma droga genérica e sem consumidor, envolvida apenas nos circuitos de operações policiais. Os transportadores, ou motoristas, são categorizados como suspeitos de tráfico e são encaminhados a delegacias e distritos policiais, o que parece produzir um sentido de resolução do fato social. Essa forma de tratar o objeto, por conseguinte, parece desempenhar uma função de legitimação das operações policiais e das prisões que delas decorrem.

Classe 4: Mercadoria de fronteira. Junto à classe 1, a classe 4 compõe o eixo chamado "Maconha: um caso de polícia". Assim como a classe anterior, a classe 4 aborda a maconha como uma mercadoria do tráfico de drogas que é apreendida pela polícia. Entre as palavras mais características, encontram-se, novamente, termos que remetem a um vocabulário policial, como polícia, apreendidos, entre outros. Por outro lado, os trechos dessa classe não relacionam a droga a suspeitos ou transportadores, mas principalmente a domínios geográficos, conforme o trecho seguinte:

Policiais do DOF (departamento de operações de fronteira) do Mato Grosso do Sul apreenderam, na tarde deste sábado, 18, quase $30 \mathrm{~kg}$ de maconha na MS-289, na região do municipio de Coronel Sapucaia, $416 \mathrm{~km}$ de Campo Grande.

Nesse contexto, a cannabis é nomeada como "maconha" e não apenas como uma droga de forma genérica. Ela é discutida, novamente, como um produto de apreensões policiais relacionadas à logística do tráfico de drogas. Notadamente, é possível perceber a presença de referências à região do Mato Grosso do Sul e da atividade específica de policiais do Departamento de Operações de Fronteiras (DOF). Essa presença aponta uma rota específica do tráfico de drogas, aquela que é estabelecida entre o Paraguai e o Brasil, através do município de Ponta Porã, conforme aborda Magalhães (2000). Ressalta-se que essa rota é utilizada costumeiramente para o tráfico de cocaína, ao passo que a maconha encontrada no Brasil é, em geral, produzida internamente. Desse modo, a "maconha" pode ter sido ressaltada como uma mercadoria específica por representar uma ruptura da ordem cotidiana que caracteriza as práticas policiais de combate ao tráfico de drogas daquele contexto.

Nesse primeiro eixo, o uso do vocábulo "polícia" aparece 622 vezes, em relação a 752 de todo o material. Isso significa que em cerca de $83 \%$ das vezes que a "polícia" foi mencionada, esse uso fez parte das classes 1 e 4 . O discurso implícito a essas duas classes é o de que a maconha é um objeto que deve ser combatido, retirado da sociedade brasileira e do circuito macroeconômico das drogas. $\mathrm{O}$ consumo da droga para quaisquer fins não é implicado nas produções desse eixo, sendo a palavra "uso" uma ausência significativa tanto da classe $1\left(\chi^{2}=-63\right)$, quanto da classe $4\left(\chi^{2}=-15\right)$. Outra ausência significativa é o termo "legalização" e suas variações na classe $1\left(\chi^{2}=-68\right)$ e na classe $4\left(\chi^{2}=-17\right)$. O segundo eixo, por sua vez, aparece ligado às ambiguidades que o uso da maconha produz dentro do contexto proibicionista, colocando em tensão essa norma de interdição.

\section{Eixo 2: Uso de Maconha e Tensões Normativas}

Classe 2: Do pequeno consumo à discussão pública. Nessa classe, são apresentados discursos sobre fatos que usualmente seriam compreendidos como pertencentes à vida privada, mas que ganham, por distintas razões, o caráter de interesse público. Nota-se que essa não é uma classe tão homogênea em termos de conteúdo, sendo o uso do vocabulário em relação aos temas encontrados o que garante coesão interna. Em primeiro lugar, observam-se palavras relacionadas ao meio artístico, tais como música, atriz e rapper, assim como nomes de pessoas desse contexto, como 
o do rapper Snoop Dogg e do baterista da banda AC/DC, Phil Rudd. Assim, o primeiro tema que se destaca nessa classe é referente ao consumo de maconha por pessoas conhecidas publicamente:

A atriz Cameron Diaz disse, durante entrevista no programa Lopez Tonight, que o rapper Snoop Dogg já lhe deu maconha no colégio.

Justin Timberlake revelou que fuma maconha regularmente para relaxar e fazer seu cérebro desacelerar.

As matérias desse tema são apresentadas como notícias de caráter extraordinário, a partir de relatos pessoais, os quais produzem um sentido de revelação pessoal em que os sujeitos "admitem" usar ou ter usado maconha em determinadas circunstâncias. Como se sabe, há uma maior aceitação do uso de maconha entre a chamada classe artística desde os anos 80 (MacRae \& Simões, 2003). Essa aceitação é acompanhada de uma tolerância legal, evidenciada nos dados analisados pela relação inversa entre os usos por pessoas famosas e termos como polícia $\left(\chi^{2}=-80\right)$ e delegacia $\left(\chi^{2}=-15\right)$. Apesar disso, é preciso notar que esses fatos são construídos socialmente em meio a uma regulação moral daquilo que é tolerado e do que é tratado como um problema, de modo que a notícia, em si, funciona como um princípio gerador de tomadas de posição sobre o objeto ou acontecimento noticiado.

Ademais, a classe 2 não reúne apenas matérias sobre famosos que usam maconha. Nessa classe, existem também trechos que tratam de acontecimentos não usuais, ou inesperados, que mobilizam questões jurídico-morais, conforme os seguintes trechos indicam:

Uma americana admitiu ter dado maconha para a filha de 2 anos e usado o celular para gravar a criança fumando.

Três empregados de uma empresa na cidade de Victoria, no Canadá, passaram mal após uma colega ter inadvertidamente dado a eles brownies de chocolate feitos com maconha.

Embora esses enunciados tratem de fenômenos distintos daqueles dedicados a noticiar o uso de maconha por pessoas famosas, eles se aproximam pelo sentido de não familiaridade ou surpresa, que é produzido pela notícia. De acordo com Motta (2006), as notícias, em geral, são relatos do que acontece no mundo, entretanto, não é todo fato cotidiano que parece interessar, mas somente aqueles que são vinculados a uma ruptura, uma quebra da normalidade. A quebra da normalidade dos enunciados dessa classe parece se relacionar ora com a revelação da pessoa que utiliza a maconha - figuras conhecidas publicamente, ora com as circunstâncias em que esse uso ocorre, como os casos de uso involuntário e/ou por crianças. A maconha, ao seu turno, toma a forma de um objeto que pode ser tolerado, mas também rechaçado e cujo uso individual merece ser noticiado quando causa algum tipo de ruptura no cotidiano.
Além disso, parece chamar atenção o caráter ambíguo ou ambivalente que se reveste a notícia quando o objeto é relacionado a artistas e outros famosos. $\mathrm{O}$ fato de o uso de maconha ser compreendido como um fato a ser noticiado, quando utilizado por essas pessoas, pode estar relacionado a uma regulação moral - e não legal - articulada à necessidade de saber sobre a vida do outro, que "assume" ou "admite" suas práticas privadas.

Classe 6: A dimensão coletiva do uso e a legalização. Se a classe 2 refere-se ao uso de maconha em pequena escala, a classe 6 , por sua vez, trata da dimensão coletiva e política do objeto. Os discursos presentes nessa classe concernem ao tema da regulação legal da maconha pelo mundo, destacando-se o tema das mudanças de legislação. Como é possível observar no dendrograma, entre as palavras mais características destacam-se vocábulos relacionados aos modelos políticos praticados no campo. Essa discussão é objetivada particularmente nas transformações vivenciadas nos últimos anos pelos Estados Unidos da América (EUA), ainda que faça referências a outros países como Uruguai, México, Colômbia, Holanda e, de forma menos expressiva, ao Brasil.

Os conteúdos dessa classe possuem estreita relação com o fenômeno do proibicionismo e da chamada "guerra contra as drogas". Por proibicionismo entende-se o modelo moral e político a partir do qual o Estado deve proibir determinadas substâncias e reprimir o seu comércio e consumo. De acordo com Rodrigues (2008), essa doutrina, que se expressa não só no campo legal, mas nas culturas de forma geral, tem sido adotada como modelo privilegiado para lidar com o uso de drogas. Por outro lado, essa estratégia política tem sido acompanhada pelo aumento tanto no número de usuários de drogas ilícitas, superlotações nas prisões, como nos gastos públicos despendidos pelos governos na tentativa de reprimir o consumo e o tráfico (Burgierman, 2011).

Tais consequências têm levado à emergência de um discurso de que o proibicionismo total é uma estratégia fracassada na forma de lidar com as drogas e muitas nações têm proposto modelos políticos alternativos à repressão. Nesse contexto de negociação de normas proibicionistas, a maconha tem adquirido importância privilegiada, tanto pela sua relevância social, como, possivelmente, pelas possibilidades de uso terapêutico, industrial, ou mesmo por ser socialmente considerada uma droga menos danosa em relação a outras. Por exemplo, em 2012 começaram a surgir propostas concretas de regulamentação da maconha para fins recreativos nos EUA, o que culminou na sua aprovação em estados como Washington e Colorado. Na América do Sul, em 2013, o governo do Uruguai decidiu pela regulamentação do consumo, produção e comercialização da maconha, com o objetivo de enfraquecer o poderio do tráfico ilegal, sendo esse o primeiro país do mundo a regulamentar a droga. Esses acontecimentos demonstram que o debate sobre o status legal da cannabis tem se intensificado nos últimos anos, repercutindo diretamente no debate sobre a regulação 
política do objeto. A classe 6, por sua vez, se relaciona a essa questão e faz referência direta às transformações citadas, conforme exemplificado nos seguintes trechos:

Dezesseis dos 50 estados americanos, assim como o distrito de Columbia (Washington), legalizaram, nos últimos anos, o uso da maconha para fins terapêuticos.

O governo do Uruguai apresentou, nesta quarta feira, um projeto de lei para a legalização controlada da maconha, em uma medida para tentar diminuir a criminalidade decorrente do narcotráfico.

O Brasil, por sua vez, tem se inserido timidamente no debate sobre a reformulação política na forma de lidar com a maconha e outras drogas. Nessa classe, por exemplo, o tema aparece relacionado ao deputado Paulo Teixeira, sob a forma de opinião isolada: "O deputado Paulo Teixeira, líder do PT na câmara, defende que o governo deveria regulamentar o plantio da maconha e autorizar a criação de cooperativas de usuários". Conforme Burgierman (2011) comenta, ainda que se aborde a discussão no Brasil, a forma de tratar o tema surge em meio a muito receio, de modo que poucos políticos se arriscam a propor mudanças, uma vez que aqueles que o fazem são costumeiramente referidos como defensores das drogas. Apesar disso, o deputado Jean Wyllys (PSOL-RJ) protocolou, em 2014, um projeto de lei $\left(\mathrm{n}^{\circ} 7270 / 2014\right)$ que propunha a regulamentação da produção e comercialização da maconha para uso recreativo, médico e industrial, mas até o momento essa proposta não foi votada. Além dessa, existem ainda mais duas propostas legislativas em curso: um projeto de lei ( $\left.\mathrm{n}^{\circ} 7187 / 2014\right)$, formulado pelo deputado Eurico Junior (PV-RJ), e outra, fruto de iniciativa popular, tem o senador Cristovam Buarque (PPS) como relator.

Além do tema sobre as transformações legais ocorridas no campo, a presença do México nessa classe contempla conteúdos de outra natureza temática. Desse modo, as relações desse país com a maconha são ancoradas no tema do tráfico internacional de drogas que ocorre na fronteira com os EUA. Os conteúdos desse subtema são apresentados de modo similar ao que foi encontrado na classe 2 , conforme é possível de ser ilustrado pelo seguinte trecho: "Autoridades mexicanas anunciaram ontem ter descoberto um túnel clandestino, ligando México e Estados Unidos e 4,5 toneladas de maconha dentro dele". Assim, os discursos em que o México se insere trazem a maconha como objeto do tráfico, de modo pouco relacionado a fenômenos de consumo e, muito menos, ao uso medicinal, como os discursos sobre as políticas americanas o fazem. O que faz com que esses discursos pertençam a essa classe é o vocabulário utilizado, ou seja, as referências realizadas a instâncias governamentais e relações internacionais. Como o próprio nome da classe sugere, são discursos que incutem a dimensão de regulação estatal por parte das nações.

Por fim, observa-se um campo discursivo bastante diverso sobre o tema da regulação da maconha. Identifica-se nessa classe argumentos relacionados ao uso recreativo e medicinal, assim como ao tráfico de drogas e às relações entre países fronteiriços. A maconha é construída como um objeto polêmico, mas ao mesmo tempo de relevância para lidar com temas diversos. Entre esses, conforme evidenciado anteriormente, existe o campo da saúde e dos potenciais terapêuticos da droga, tema que caracteriza o conteúdo da classe 5 .

Classe 5: Ciência, saúde e uso medicinal. A classe 5 concentra as formas de discurso da saúde e do uso terapêutico da maconha, como observado na Figura 1. O vocabulário empregado remete particularmente ao saber da medicina sobre o uso de maconha, relação que fica clara pela forte presença de termos como paciente, doença, efeito, saúde, psiquiatria, entre outros. Dentre os conteúdos da classe, estão incluídas as matérias que trazem resultados de pesquisas no âmbito da medicina - psiquiatria e neurologia, principalmente-, tanto sobre os efeitos danosos da maconha, como das suas potencialidades terapêuticas:

O estudo, produzido por cientistas da universidade de farmacologia de Bristol (Inglaterra), analisou os efeitos negativos da maconha na memória e no pensamento, o que pode provocar redes cerebrais desorquestradas.

Na década de 1990, pesquisadores identificaram receptores capazes de responder ao tetrahidrocanabinol (THC). (...) Essa descoberta revelou que substâncias muito semelhantes existem naturalmente em nosso organismo, permitiu avaliar em detalhes seus efeitos terapêticos e abriu perspectivas para o tratamento da obesidade, esclerose múltipla, doença de Parkinson.

Conforme é possível notar, o vocabulário utilizado remete a um contexto de produção especializado, em que termos técnicos relacionados ao campo de pesquisa ou da clínica médica são utilizados para tratar dos efeitos da maconha no corpo humano, especialmente no cérebro. A droga é relacionada a efeitos negativos, como ao desenvolvimento de esquizofrenia, dependência, danos cerebrais, prejuízos relacionados à memória, câncer de pulmão e bronquite. Por outro lado, em outras matérias a maconha é apontada como possibilidade de tratamento, ou como medicamento auxiliar, para anorexia, Parkinson, depressão, ansiedade, fobia social, dor crônica e câncer.

Estudos realizados sobre o potencial terapêutico da maconha têm demonstrado efeitos positivos no controle de náuseas e vômitos, por exemplo, ou mesmo na estimulação do apetite em pacientes com câncer ou com síndrome da imunodeficiência adquirida - AIDS (Bordin, Jungerman, Figlie, \& Laranjeira, 2010; Carlini, 2006; Organização Mundial de Saúde, 2006). Além disso, seus efeitos analgésicos e anticonvulsivantes são algumas vezes descritos como clinicamente relevantes, mas demandam ainda mais pesquisas (Bordin et al., 2010; OMS, 2006). Além dessas possibilidades, a cannabis tem sido considerada como uma estratégia de redução de danos para lidar com a fissura 
relacionada à dependência do crack (Chaves, Sanchez, Ribeiro, \& Nappo, 2011; Ribeiro, Sanchez, \& Nappo, 2010) ou ainda como uma forma de terapia de substituição potencialmente proveitosa, nos casos de dependência de outras drogas (MacRae \& Gorgulho, 2003).

De modo geral, ainda que os danos decorrentes do uso crônico de maconha sejam bastante salientes nessa classe, os conteúdos relacionados aos seus efeitos terapêuticos potenciais constituem um dado importante, sobretudo em comparação a outros resultados disponíveis na literatura. Em pesquisa que analisou os conteúdos sobre drogas veiculados em uma revista de grande circulação no Brasil (Ronzani et al., 2009), houve menções a danos do consumo de maconha, mas não foram encontradas referências a nenhum tipo de benefício ligado ao objeto. Por outro lado, em outra pesquisa, que analisou a difusão de conteúdos relacionados às drogas no campo da saúde a partir de matérias de jornais e revistas (Noto et al., 2003), observou-se que pouco mais da metade dos artigos sobre maconha mencionavam benefícios terapêuticos potenciais. As diferenças nos resultados dessas pesquisas favorecem a interpretação de que a inscrição da maconha no âmbito da saúde é marcada pela saliência temática dos seus benefícios, denotando a existência de ambiguidades valorativas do objeto, a depender do tipo de contexto em que ele é ancorado.

É preciso observar que a classe temática sobre a regulação estatal da maconha fazia referências diretas ao uso medicinal da droga, por outro lado, a ênfase naquele contexto residia na dimensão coletiva do objeto em face da sua condição legal. Na classe 5 , entretanto, a maconha surge como um objeto que, embora também seja relacionado ao uso medicinal, é produzido em um discurso ancorado no conhecimento científico, aparentemente isolado das relações políticas que esse uso necessariamente implica. Nesse sentido, como um objeto de pesquisa, a maconha é aqui classificada como cannabis, em clara referência à nomenclatura taxonômica da planta na biologia. Esse tratamento diferenciado ancora o objeto nos saberes da medicina, neurologia e biologia ao mesmo tempo em que visa retirar a tensão moral que o termo "maconha" pode produzir. O uso da palavra cannabis, nesse contexto, se dá no sentido de produzir um sentido de neutralidade política, adequando o conteúdo a expectativas sociais relacionadas à própria produção do conhecimento científico.

Além disso, os dados mencionam frequentemente duas categorias identitárias: os pesquisadores e os pacientes. Os pesquisadores são apresentados como representantes do conhecimento científico que, através desse tratamento, conferem legitimidade aos argumentos produzidos pelo jornal. Um exemplo disso é o uso de outros termos, como "cientistas" e "comprovam" de forma acompanhada. De acordo com Motta (2006), é comum abordar técnicos ou especialistas nas comunicações jornalísticas, tendo por função demarcar e legitimar lugares sociais. Os pesquisadores são, portanto, inseridos nas matérias como aqueles responsáveis por falar sobre dada realidade: os efeitos positivos e negativos da maconha para a saúde. Os pacientes, por sua vez, não são trazidos como usuários, mas categorizados como doentes, como aqueles que portam determinado transtorno e podem precisar de tratamento com cannabis. O que subjaz esse discurso é, então, a legitimação de uma possibilidade de uso, ou seja, em casos de doença, desligando o objeto da dimensão do prazer relacionada ao consumo recreativo - esse sim moralmente desqualificado. Com isso, não só a maconha é produzida como um objeto da medicina, mas o próprio usuário é compreendido a partir de um referencial patológico.

Classe 3: A marcha da maconha. A última classe reúne as matérias relacionadas à marcha da maconha, um movimento social que promove atos políticos em diversas cidades do Brasil, no sentido de fortalecer a discussão sobre a regulamentação da maconha. Como observado na Figura 1, o vocabulário característico da classe 3 faz referência aos atos e passeatas, bem como a algumas tensões geradas pela ancoragem do movimento no campo do direito. Ainda que a marcha tenha sido tratada como um movimento, é notório que o tema central da classe é a realização dos atos públicos e suas consequências jurídicas, conforme é possível observar a seguir:

No rio, o juiz Alberto fraga, do $4^{\circ}$ juizado especial criminal, concedeu habeas corpus preventivo, garantindo que os manifestantes não serão presos. Já em Vitória, o ministério público acionou a justiça, pedindo a proibição do movimento. Na ação, o promotor Marcos Antônio Rocha Pereira afirmou que a marcha consistiria em apologia ao crime.

No início de 2011, a realização da marcha da maconha foi proibida judicialmente em várias capitais brasileiras, sob o argumento de que o movimento faria apologia ao uso de drogas ilícitas. Apesar dessas proibições, algumas manifestações foram realizadas ainda com o nome de marcha da maconha e outras, como uma forma de lidar com a interdição, adotaram o nome de marcha da liberdade. Nesses atos, algumas capitais presenciaram conflitos entre participantes da marcha e a polícia. Em 15 de junho desse mesmo ano, o Supremo Tribunal Federal (STF) considerou equivocadas as proibições realizadas e argumentou que o movimento tratava de um exercício de liberdade política e de expressão, liberando, por fim, a realização dessas manifestações no Brasil (Brandt, 2011).

No contexto analisado, a marcha da maconha surge como um ponto de tensão normativa capaz de gerar tomadas de posição avaliativas sobre o movimento e suas pautas políticas. Por um lado, há aqueles que compreendem o evento como uma prática criminosa (apologia ao uso de drogas ilícitas) e, por outro, aqueles que conferem legitimidade à sua realização, sejam esses aderentes à causa da marcha ou não. Os argumentos da marcha não são discutidos 
nos enunciados e, de forma muito breve, o movimento é descrito como pró-legalização: "O evento reúne, em diversas cidades brasileiras, manifestantes favoráveis à legalização da droga”. O que se produz com essas matérias, então, é a discussão da legitimidade da marcha da maconha e não as implicações sociais e políticas do movimento. $\mathrm{O}$ movimento da marcha pode ser considerado, assim, uma minoria ativa (Moscovici, 2011), tanto pelo seu caráter contranormativo diante do proibicionismo, como pelo fato de ser dirigido à transformação social. Não obstante, a ênfase sobre a legitimidade do movimento parece indicar uma tentativa de desqualificação das pautas antiproibicionistas na cena pública brasileira através do apelo a autoridades institucionais, como juízes, ministros e promotores.

Conforme se depreende da discussão realizada, o segundo apresenta uma heterogeneidade maior de conteúdo em relação ao primeiro eixo. Em outras palavras, esse eixo parece se constituir em oposição ao primeiro e não, de forma homogênea, a partir das proximidades temáticas das classes que o compõem. Com isso, é possível dizer que o que unifica as classes 2, 6, 5 e 3 é a própria desvinculação do objeto do discurso policial relacionado à repressão das drogas. Isso é ilustrado pela relação inversa que essas quatro classes, respectivamente, têm com os termos "polícia" $\left(\chi^{2}=-80\right.$; $-257 ;-92 ;-31)$ e variações de "apreensão" $\left(\chi^{2}=-33 ;-69\right.$; $-15 ;-27)$. Nesse eixo, a maconha é distanciada do discurso do tráfico de drogas e evidencia as tensões normativas do objeto (uso privado e público em contexto que o proíbe).

Em que pese essa observação, ressalta-se que os dois eixos são constituídos e constitutivos de representações sociais, apontando para diferentes dimensões do objeto na cena pública. A construção da cannabis como uma mercadoria do tráfico é objetivada nas apreensões policiais que descrevem, inclusive, o peso e outras características da droga apreendida; a maconha como um medicamento toma forma nos relatos de tratamento de pacientes com HIV e câncer; como uma droga psicoativa, ela se concretiza a partir dos usos por pessoas famosas e acontecimentos polêmicos; como objeto regulado legalmente, a cannabis é objetivada nas transformações políticas internacionais e na marcha da maconha.

Além disso, os diferentes campos nos quais a maconha se insere repercutem ativamente no modo como ela é considerada. Esse processo de ancoragem lida diretamente com as relações linguísticas e de sentido que são construídas em torno do objeto a partir dos diferentes contextos comunicativos em que ele se inscreve. Nesse sentido, ressaltamos que a palavra droga é especificamente utilizada no contexto da maconha como um caso de polícia, o que confere à maconha um enraizamento concreto vinculado à sua ilicitude. Enquanto que o uso de cannabis marca a inserção do objeto no universo da saúde e do uso medicinal, conferindo, assim, um status simbólico atrelado ao cuidado.

\section{CONSIDERAÇÕES FINAIS}

Os resultados trabalhados não parecem apontar uma forma única de construção da maconha, que aparece tematizada por dois universos de discurso: a repressão policial e a tensão normativa atrelada às suas formas e finalidades de consumo. É possível afirmar que os usos da maconha e seu status legal são os principais elementos que estruturam a divisão dos dados em dois campos discursivos que se opõem. O caráter ilícito da maconha, que aparece no segundo eixo, adquire novos contornos e aparece como uma questão política (e não mais como um problema de polícia), visto que ele põe em pauta princípios geradores de tomadas de posição a respeito de diferentes modos de uso (terapêutico e recreativo), em dimensões públicas e privadas.
A maconha é, assim, distanciada do discurso do tráfico de drogas e evidencia processos de negociação simbólica em torno do objeto.

Cabe ressaltar, ainda, que o estudo foi realizado em apenas um jornal que, embora tenha grande penetração nacional, pode não refletir a diversidade de pensamento social que circula sobre a maconha em produções midiáticas. Por fim, é preciso considerar as comunicações analisadas como produtos culturais cujos efeitos vão além da função informativa. Elas produzem identidades, legitimam práticas e instituições e participam ativamente da (re)elaboração discursiva da maconha no Brasil. 


\section{REFERÊNCIAS}

Banchs, M. A. (2011). Leitura epistemológica da teoria das Representações Sociais. Reflexões rumo a um sentido comum menos comum e com mais sentido. In A. M. O. Almeida, M. F. S. Santos, \& Z. A. Trindade (Orgs.), Teoria das Representações Sociais: 50 anos (pp. 225-258). Brasília: Technopolitik.

Blanco, C., Hasin, D. S., Wall, M. M., Flórez-Salamanca, L., Hoertel, N., Wang, S., ... Olfson, M. (2016). Cannabis use and risk of psychiatric disorders: Prospective evidence from a US national longitudinal study. JAMA Psychiatry, 73(4), 388-395.

Bordin, S., Jungerman, F. S., Figlie, N. B., \& Laranjeira, R. (2010). Maconha. In N. B. Figlie, S. Bordin, \& R. R. Laranjeira (Orgs.), Aconselhamento em dependencia quimica (2 ed., pp. 119-131). Sao Paulo: Roca.

Brandt, F. (2011). STF decide que ato por legalização de drogas é liberdade de expressão e libera Marcha da Maconha. Recuperado de http://noticias.uol.com.br/cotidiano/ultimasnoticias/2011/06/15/stf-decide-que-ato-por-legalizacaode-drogas-e-liberdade-de-expressao-e-libera-marcha-damaconha.htm

Brasil. Dispõe sobre a atualização do Anexo I (Listas de Substâncias Entorpecentes, Psicotrópicas, Precursoras e Outras sob Controle Especial) da Portaria SVS/MS n 344, de 12 de maio de 1998, e dá outras providências, Pub. L. No. RDC n ${ }^{0} 66$ de 18 de março de 2016 (2016). Recuperado de http://portal.anvisa.gov.br/ documents/33864/340935/RDC+n\%C2\%BA+66,+de+18-032016/381cb13b-3ac1-4948-a12a-8c8a6d24677f

Bucher, R., \& Oliveira, S. (1994). O discurso do "combate às drogas" e suas ideologias. Revista de Saúde Pública, 28(2), 137-145.

Burgierman, D. R. (2011). O fim da guerra: A maconha e a criação de um novo sistema para lidar com as drogas. São Paulo: Leya.

Carlini, E. A. (2006). A história da maconha no Brasil. Jornal Brasileiro de Psiquiatria, 55(4), 314-317.

Carlini, E. A., Galduróz, J. C. F., Silva, A. A. B., Noto, A. R., Fonseca, A. M., Carlini, C. M. de A., ... Sanchez, Z. M. (2006). II Levantamento domiciliar sobre o uso de drogas psicotrópicas no Brasil: Estudo envolvendo as 108 maiores cidades do país 2005. São Paulo: CEBRID - Centro Brasileiro de Informações sobre Drogas Psicotrópicas.

Carlini, E. A., Noto, A. R., Sanchez, Z. M., Carlini, C. M. de A., Locatelli, D. P., Amato, T. de C., ... Moura, Y. G. (2010). VI Levantamento nacional sobre o consumo de drogas psicotrópicas entre estudantes do ensino fundamental e médio das redes pública e privada de ensino nas 27 capitais brasileiras - 2010. Säo Paulo, SP: CEBRID - Centro Brasileiro de Informações sobre Drogas Psicotrópicas.

Chaves, T., Sanchez, Z. V. D. M., Ribeiro, L. A., \& Nappo, S. A. (2011). Fissura por crack: Comportamentos e estratégias de controle de usuários e ex-usuários. Revista de Saúde Pública, 45(6), 1168-75.

Doise, W. (2011). Sistema e metassistema. In A. M. O. Almeida, M. F. S. Santos, \& Z. A. Trindade (Orgs.), Teoria das Representações Sociais: 50 anos (pp. 123-156). Brasília: Technopolitik.

Espíndula, D. H. P., Alves, L. dos S., Carvalho, L. de A., Almeida, M. B., \& Cruz, S. T. M. (2015). Representações sociais de crack e adolescência na imprensa pernambucana. Temas em Psicologia, 23(2), 281-292. https://doi.org/10.9788/ TP2015.2-04

França, J. M. C. (2015). História da maconha no Brasil. São Paulo: Três Estrelas.

Jodelet, D. (1984). Réflexions sur le traitement de la notion de représentation sociale en psychologie sociale. Communication information, 6(2/3), 15-42.
Jodelet, D. (2001). Um domínio em expansão. In D. Jodelet (Ed.), As representações sociais (pp. 17-44). Rio de Janeiro: EdUERJ. Justo, A. M., \& Camargo, B. V. (2014). Estudos qualitativos e o uso de softwares para análises lexicais. In C. Novikoff, S. R. M. Santos, \& O. B. Mithidieri (Orgs.), Caderno de artigos: X SIAT \& II Serpro (2014: Duque de Caxias, RJ, pp. 37-54). Duque de Caxias: UNIGRANRIO. Recuperado de http://www. academia.edu/download/37180083/Justo_Camargo_2014.pdf

Kalampalikis, N., \& Moscovici, S. (2005). Une approche pragmatique de l'analyse Alceste. Cahiers Internationaux de Psychologie Sociale, (2), 15-24.

MacRae, E., \& Gorgulho, M. (2003). Redução de danos e tratamento de substituição: Posicionamento da Rede Brasileira de Redução de Danos. Jornal Brasileiro de Psiquiatria, 52(5), 371-374.

MacRae, E., \& Simões, J. A. (2003). A subcultura da maconha, seus valores e rituais entre setores socialmente integrados. In M. Baptista, M. S. Cruz, \& R. Matias (Orgs.), Drogas e pósmodernidade: Faces de um tema proscrito. Rio de Janeiro: EdUERJ.

Magalhães, M. (2000). O narcotráfico. São Paulo: PubliFolha.

Moscovici, S. (2009). Representações sociais: Investigações em psicologia social ( $6^{\mathbf{a}}$ ed). Petrópolis: Vozes.

Moscovici, S. (2011). Psicologia das minorias ativas. Petrópolis: Vozes.

Moscovici, S. (2012). A psicanálise, sua imagem e seu público. Petrópolis: Vozes.

Motta, L. G. (2006). Notícias do fantástico: Jogos de linguagem na comunicação jornalística. São Leopoldo: Unisinos.

Nascimento, A. R. A., \& Menandro, P. R. M. (2006). Análise lexical e análise de conteúdo: Uma proposta de utilização conjugada. Estudos e Pesquisas em Psicologia, 6(2), 72-88.

National Institute on Drug Abuse. (2016). Marijuana: Research Report Series. Bethesda: National Institute on Drug Abuse. Recuperado de https://www.drugabuse.gov/publications/ research-reports/marijuana

Noto, A. R., Baptista, M. C., Faria, S. T., Nappo, S. A., Galduróz, J. C. F., \& Carlini, E. A. (2003). Drogas e saúde na imprensa brasileira: uma análise de artigos publicados em jornais e revistas. Cadernos de Saúde Pública, 19(1), 69-79.

Oliveira, F. da C., Gianordoli-Nascimento, I. F., Santos, T. L. A. dos, \& Freitas, J. C. de. (2015). Fronteiras e pertenças: Representações sociais e dinâmicas identitárias do tráfico de drogas na revista Veja (1968-2010). Psicologia e Saber Social, 4(2), 277-297. https://doi.org/10.12957/psi.saber. soc. 2015.12385

Organização Mundial de Saúde. (2006). Neurociência do uso e da dependência de substâncias psicoativas (F. Corregiari, Trad.). São Paulo: Roca.

Pernisa, C., \& Alves, W. (2010). Comunicação digital: Jornalismo, narrativas, estética. Rio de Janeiro: Mauad X.

Pinto, A. E. de S. (2012). Folha. São Paulo, SP: Publifolha

Reinert, M. (2000). Alceste: Un logiciel d'aide pour l'analyse de discours. Notice simplifiée (de la version de base commune aux versions 4x) [Manual]. Université de Versailles SaintQuentin-en-Yvelines, Versailles, França. Retirado de http:// tic-recherche.crifpe.ca/docs/guides/fr/Alceste_guide.pdf.

Ribeiro, L. A., Sanchez, Z. V. D. M., \& Nappo, S. A. (2010). Estratégias desenvolvidas por usuários de crack para lidar com os riscos decorrentes do consumo da droga. Jornal Brasileiro de Psiquiatria, 59(3), 210-218.

Rodrigues, T. (2008). Tráfico, guerra, proibição. In B. C. Labate, S. L. Goulart, M. Fiore, E. MacRae, \& H. Carneiro (Orgs.), Drogas e cultura: Novas perspectivas (pp. 105-120). Salvador: EDUFBA. 
Rodrigues, D. R. S. da R., Conceição, M. I. G., Iunes, A. L. da S. (2015). Representações sociais do crack na mídia. Psicologia: Teoria e Pesquisa, 31(1), 115-123. https://doi. org/10.1590/0102-37722015010994115123

Ronzani, T. M., Fernandes, A. G. B., Gebara, C. F. de P., Oliveira, S. A., Scoralick, N. N., \& Lourenço, L. M. (2009). Mídia e drogas: Análise documental da mídia escrita brasileira sobre o tema entre 1999 e 2003. Ciência \& Saúde Coletiva, 14(5), $1751-1761$.

Santos, M. de F. de S., Acioli Neto, M. L., \& Sousa, Y. S. O. (2012). Representações sociais do crack na imprensa pernambucana. Estudos de Psicologia (Campinas), 29(3), 379-386. https:// doi.org/10.1590/S0103-166X2012000300008

Simoneau, A. S., \& Oliveira, D. C. (2014). Representações sociais e meios de comunicação: Produção do conhecimento científico em periódicos brasileiros. Psicologia e Saber Social, 3(2), $281-300$
United Nations Office on Drugs and Crime. (2016). World Drug Report 2016. New York: United Nations Publication.

Velho, G. (1994). A dimensão cultural e política dos mundos das drogas. In A. Zaluar (Org.), Drogas e cidadania: Repressão ou redução de riscos (p. 23-29). São Paulo: Editora Brasiliense.

Wagner, W. (1998). Social representations and beyond: Brute facts, symbolic coping and domesticated worlds. Culture \& Psychology, 4(3), 297-329.
Submetido: $11 / 11 / 2014$

Revisado: 07/12/2016

Aceito: 21/01/2017 